\title{
Near-infrared photoluminescence of erbium tris(8-hydroxyquinoline) spin-coated thin films induced by low coherence light sources
}

\author{
S. Penna ${ }^{a)}$ and A. Reale \\ Dipartimento di Ingegneria Elettronica, Università degli studi di Roma “Tor Vergata," Viale Politecnico 1, \\ 00133 Roma, Italy \\ R. Pizzoferrato \\ Dipartimento di Ingegneria Meccanica, Università degli studi di Roma "Tor Vergata," Viale Politecnico 1, \\ 00133 Roma, Italy
}

G. M. Tosi Beleffi and D. Musella

Istituto Superiore delle Comunicazioni e delle Tecnologie dell'Informazione, Viale America 201, 00144 Roma, Italy

W. P. Gillin

Department of Physics, Queen Mary, University of London, Mile End Road, London E1 4NS, United Kingdom

(Received 8 May 2007; accepted 14 June 2007; published online 10 July 2007)

\begin{abstract}
The authors present the characterization of spin-coated erbium tris(8-hydroxyquinoline) $\left(\mathrm{ErQ}_{3}\right)$ solution on glass substrates under high temperature conditions. Absorption and infrared photoluminescence, induced by laser and light emitting diode sources, were measured and compared to cast and evaporated $\mathrm{ErQ}_{3}$ samples. A broad absorption band and $1.52 \mu \mathrm{m}$ luminescence were observed, suggesting spin coating as a valid deposition technique for processing of organic infrared emitting diodes. (C) 2007 American Institute of Physics. [DOI: 10.1063/1.2755933]
\end{abstract}

In recent years, organolanthanide complexes have been widely used as emitting layers to obtain electroluminescence from organic light emitting diodes. ${ }^{1-6}$ The main advantage of these compounds lies in the large absorption cross section of the allowed $\pi-\pi^{*}$ optical transitions in the organic ligands, that acts as an efficient light harvesting antenna. ${ }^{7-9}$ This property enables optical excitation by means of low coherence and low-cost light sources, such as light emitting diodes (LEDs). Some organolanthanides have shown electroluminescence in the near-infrared range. ${ }^{10-16}$ Among the different erbium organic compounds analyzed in literature, ${ }^{7,17-19}$ erbium tris(8-hydroxyquinoline) $\left(\mathrm{ErQ}_{3}\right)$ is the most interesting organic infrared emitter because it has shown the highest photoluminescence ${ }^{20-22}$ and electroluminescence ${ }^{23-25}$ intensities centered at $1525 \mathrm{~nm}$; this corresponds to the low loss third window wavelength range used in standard optical communications. $\mathrm{ErQ}_{3}$ is a small molecule; for this reason, organic light emitting diodes based on such a compound can be manufactured using vacuum processing techniques, such as thermal evaporation. ${ }^{23-25}$ It is known that these techniques need relatively expensive vacuum systems and long time to reach the right vacuum conditions (at least $10^{-6}$ mbar). It could be useful to manufacture an $\mathrm{ErQ}_{3}$-based organic LED (OLED) using an alternative deposition process that allows for cheaper and faster processing. To achieve these goals, we focused our study on the characterization of this compound in order to demonstrate that $\mathrm{ErQ}_{3}$ OLED can be a solution processable device. Solution processing allows more flexibility for OLED implementation and design as with imprinting lithography, a promising lithographical technique that allows for an easy, cheap, and high resolution patterning of organic devices. $^{26,27}$ In this letter, we report photoluminescence char-

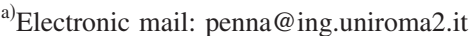

acterization of $\mathrm{ErQ}_{3}$ spin-coated sample demonstrating that the advantageous properties of this compound, i.e., wide absorption band and third window luminescence, are preserved by this deposition technique.

A solution was prepared by dissolving $\mathrm{ErQ}_{3}$ powder in dimethyl sulfoxide (DMSO) (Sigma-Aldrich), that was experimented to be the most effective solvent for $\mathrm{ErQ}_{3}$. The solution concentration was set at $1 \%$ by weight. Glass substrates (Corning) were placed in an ultrasonic chamber in acetone solution (Sigma-Aldrich) for $15 \mathrm{~min}$ and then washed in isopropyl alcohol (Carlo Erba) for $10 \mathrm{~min}$. Samples were then dried in nitrogen gas before coating processes. Due to the high boiling point of DMSO $\left(189^{\circ} \mathrm{C}\right)$, the traditional spin-coating technique is unsuccessful, resulting in nonuniform coated thin films. Uniformity of the organic layers is the basic condition for the design of any organic semiconductor device based on thin film deposition. For this reason, a dedicated spin-coating method [high temperature spin coating (HTSC)] was developed using a heat source placed over the spin-coater holder. HTSC process was performed in two subsequent steps: step one at low spinning speed $(500 \mathrm{rpm})$, to allow uniform spreading and adhesion of the solution over the whole substrate, and step two at higher speeds (from 1000 up to $2000 \mathrm{rpm}$ ) to define the thickness of the layer. Uniform thin films were obtained when both steps were performed with the substrate temperature at $110^{\circ} \mathrm{C}$. $\mathrm{ErQ}_{3}$ evaporated thin films were grown in a vacuum thermal evaporation chamber (Edwards) with a typical pressure of $0.2 \times 10^{-6}$ mbar.

Absorption spectra were obtained by means of a Cary 50 UV-vis spectrophotometer (Varian). An InGaN laser (Photonic Technologies Instruments) and an ultraviolet (UV) emitting LED (Hktaiyuen), peaking, respectively, at 406 and $402 \mathrm{~nm}$, were used as excitation sources. The LED light was focused by a system of lenses till to obtain a $1 \mathrm{~mm}^{2}$ wide 


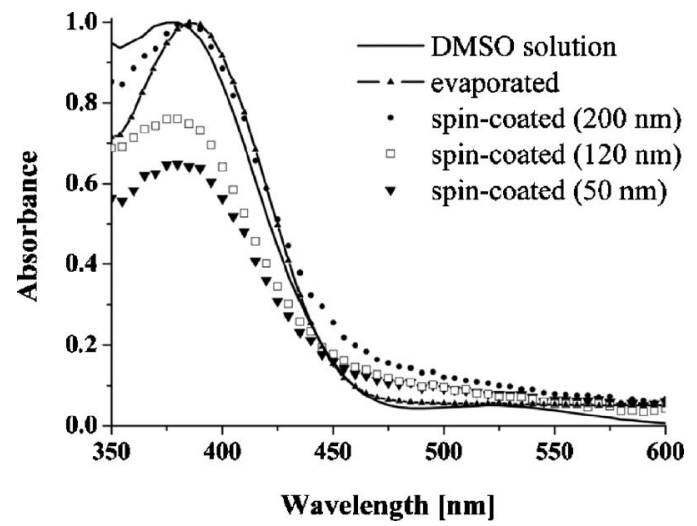

FIG. 1. Absorption spectra of $\mathrm{ErQ}_{3}$ evaporated thin film, $\mathrm{ErQ}_{3}$ solution, and $\mathrm{ErQ}_{3}$ spin-coated thin films with different thicknesses. Spin-coated spectra are normalized to the thickest sample $(200 \mathrm{~nm})$.

spot on the tested samples, in order to have a meaningful comparison between laser-induced and LED-induced luminescence. Infrared photoluminescence was detected using a thermoelectrically cooled InGaAs photodiode (Newport) while the output signal was amplified by a coherent detection system involving a lock-in amplifier (EG\&G). An Alpha Taly-Step (Tencor) was used to obtain the thickness values of spin-coated layers.

Absorption spectra of the spin-coated thin films in Fig. 1 show an absorption peak centered at $380 \mathrm{~nm}$, corresponding to one of the $\pi \rightarrow \pi^{*}$ absorption transitions of the quinoline ligand. ${ }^{21,28,29}$ Comparing these spectra to the ones related to $\mathrm{ErQ}_{3}$ evaporated thin films and $\mathrm{ErQ}_{3}$ solution, a similar behavior can be observed, suggesting that the light sensitization scheme of the material is preserved by HTSC deposition. Laser-induced photoluminescence (PL) spectra of spincoated thin films (see Fig. 2) show one peak at $1525 \mathrm{~nm}$ with an $80 \mathrm{~nm}$ full width at half maximum (FWHM). The inset shows the linear dependence of emission intensity on the thickness of spin-coated layers. Spin-coated PL spectra match PL spectra from $\mathrm{ErQ}_{3}$ solution and $\mathrm{ErQ}_{3}$ evaporated thin films ${ }^{20,22,29}$ (see Fig. 3). Although the excitation wavelength $(406 \mathrm{~nm})$ was far from the absorption peak of $\mathrm{ErQ}_{3}$ $(380 \mathrm{~nm})$, we were able to obtain infrared luminescence just exploiting the high absorption cross section of the organic ligand. Comparing the laser-induced PL spectrum and a single UV-LED-induced PL spectrum (Fig. 4), we can ob-

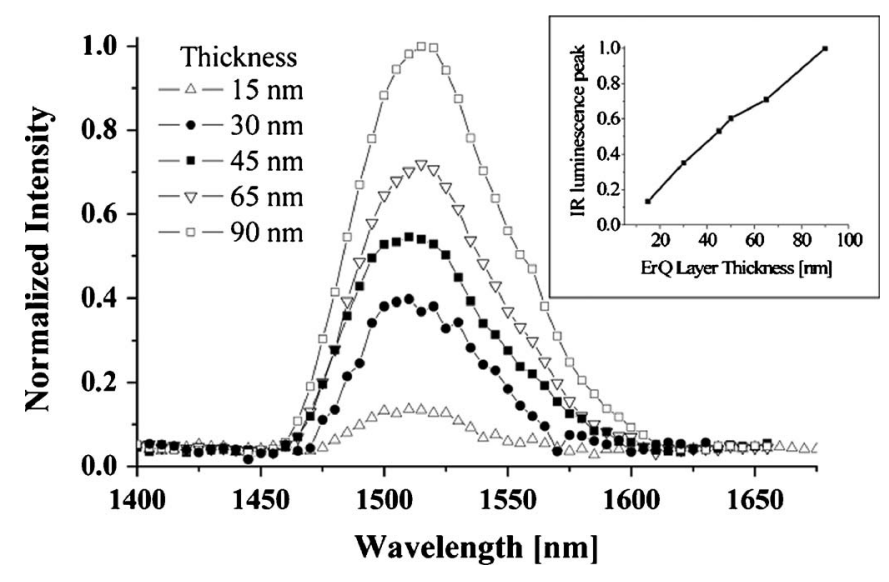

FIG. 2. Room-temperature PL spectra of $\mathrm{ErQ}_{3}$ spin-coated thin films, following laser excitation at $406 \mathrm{~nm}$. The inset shows the dependence of the IR

emission peak on the thickness of $\mathrm{ErQ}_{3}$ spin-coated thin films.
Downloaded 11 Jul 2007 to 138.37 .50 .206 . Redistribution subject to AlP license or copyright, see h

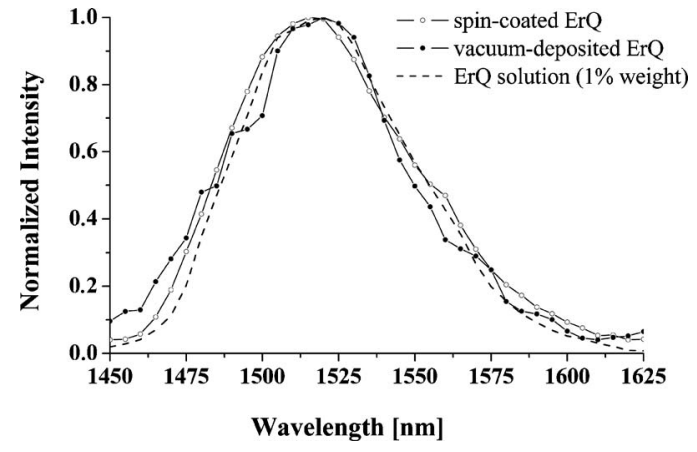

FIG. 3. Room-temperature PL spectra of $\mathrm{ErQ}_{3}$ spin-coated thin film, $\mathrm{ErQ}_{3}$ evaporated thin film, and $\mathrm{ErQ}_{3}$ solution, following laser excitation at $406 \mathrm{~nm}$.

serve that the two spectra have the same $1525 \mathrm{~nm}$ peak and similar FWHM $(80 \mathrm{~nm})$ and both present the characteristic shoulder at $1560 \mathrm{~nm}$. We can also observe that the two spectra have similar normalized intensities if we consider that the excitation power density of the focused UV-LED is $340 \mu \mathrm{W} / \mathrm{mm}^{2}$ while that for the laser source is $38 \mathrm{~mW} / \mathrm{mm}^{2}$. In such a way, we demonstrate that pumping $\mathrm{ErQ}_{3}$ by a low coherence source does not introduce efficiency loss. This is another practical demonstration of the easy and cheap optical excitation related to organolanthanides.

In summary, we have shown that it is possible to obtain uniform thin films by spin-coating deposition of $\mathrm{ErQ}_{3}$ solution, demonstrating that the most interesting properties of this compound, which are a wide absorption band and infrared photoluminescence in the third window, do not change with respect to vacuum evaporated $\mathrm{ErQ}_{3}$ thin films. This allows for the use of solution processing techniques to realize $\mathrm{ErQ}_{3}$-based infrared luminescent devices. These devices could be optically or electrically stimulated. In our opinion, $\mathrm{ErQ}_{3}$-based optically pumped devices, such as a waveguiding device, are very attractive considering that they could be pumped easily by low-cost light sources, as we demonstrated, exploiting the wide absorption spectrum of quinoline and the "antenna" sensitization scheme. In such a way, it could be possible to replace expensive high-power lasers requested for pumping erbium energy levels. $\mathrm{ErQ}_{3}$-based electrically stimulated devices, such as OLEDs, are a more com-

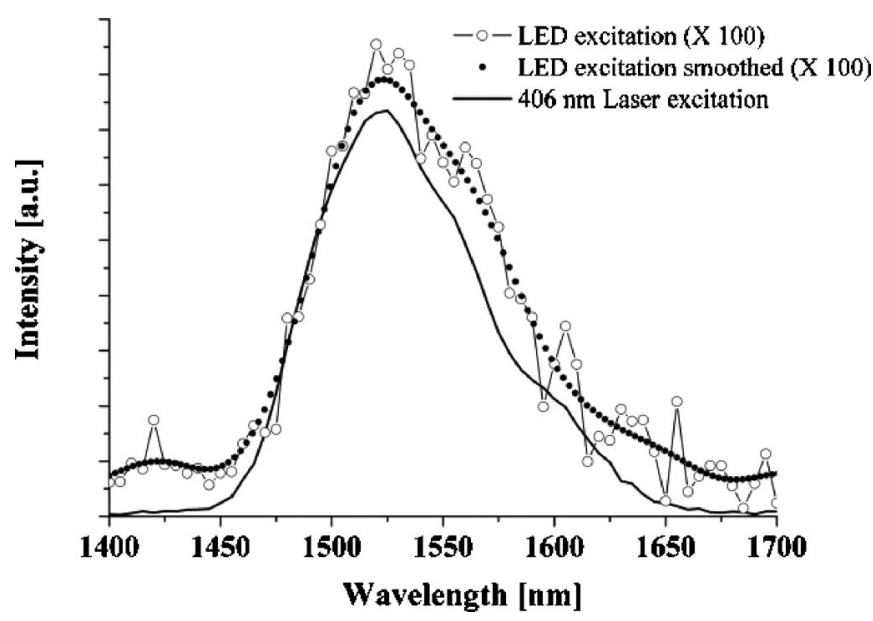

FIG. 4. Comparison between PL spectra of LED pumped spin-coated $\mathrm{ErQ}_{3}$

and laser pumped spin-coated $\mathrm{ErQ}_{3}$. 
plex target to achieve by solution processing. This is due to many causes, such as the need for full compatibility between the solvents used for dissolving materials, in order to avoid that the upper layer deposition damages the layers beneath. Another issue to consider is related to the high temperatures involved in the $\mathrm{ErQ}_{3}$ solution processing, that preclude the use of most polymers whose electrical properties are modified at temperatures higher than $120{ }^{\circ} \mathrm{C}$. Our preliminary experiments are focusing on OLED structures involving $\mathrm{ErQ}_{3}$ as active layer and blue emitting small molecules, such as $\alpha$-NPB (N, $\mathrm{N}^{\prime}$-Bis(naphthalen-1-y1)-N, $\mathrm{N}^{\prime}$-bis(phenyl)benzidine and oxadiazole-carbazole $(6,4),{ }^{30}$ as charge transport layers. Blue emission from these compounds is studied for its possible energy coupling with quinoline, that strongly absorbs up to $430 \mathrm{~nm}$. In such a way, the lost electrical excitation, due to the undesired charge recombination in the transport layers, can be partially recovered as optical excitation. We have indeed verified that low coherence sources with broad luminescence can be very efficient excitation sources for $\mathrm{ErQ}_{3}$.

One of the authors (S.P.) would like to thank ISCOM for financial support and CNR-Roma2 for thickness measurements.

${ }^{1}$ J. Kido, H. Hayase, K. Hongawa, K. Nagai, and K. Okuyama, Appl. Phys. Lett. 65, 2124 (1994).

${ }^{2}$ C. Adachi, M. A. Baldo, and S. R. Forrest, J. Appl. Phys. 87, 8049 (2000).

${ }^{3}$ J. Kalinowski, W. Stampor, M. Cocchi, D. Virgili, and V. Fattori, J. Appl. Phys. 100, 034318 (2006).

${ }^{4}$ J. Fang, H. You, J. Gao, W. Lu, and D. Ma, J. Lumin. 124, 157 (2007).

${ }^{5}$ Z. Wang and I. D. W. Samuel, J. Lumin. 111, 199 (2005).

${ }^{6}$ R. Reyes, M. Cremona, E. E. S. Teotonio, H. F. Brito, and O. L. Malta, Thin Solid Films 469-470, 59 (2004).

${ }^{7}$ S. Destri, W. Porzio, F. Meinardi, R. Tubino, and G. Salerno, Macromolecules 36, 273 (2003).

${ }^{8}$ F. Quochi, R. Orrù, F. Cordella, A. Mura, G. Bongiovanni, F. Artizzu, P. Deplano, M. L. Mercuri, L. Pilia, and A. Serpe, J. Appl. Phys. 99, 053520 (2006).
${ }^{9}$ J. Thompson, R. I. R. Blyth, G. Gigli, and R. Cingolani, Adv. Funct. Mater. 14, 979 (2004).

${ }^{10}$ F. X. Zang, W. L. Li, Z. R. Hong, H. Z. Wei, M. T. Li, X. Y. Sun, and C. S. Lee, Appl. Phys. Lett. 84, 5115 (2004).

${ }^{11}$ Y. Kawamura, Y. Wada, Y. Hasegawa, M. Iwamuro, T. Kitamura, and S. Yanagida, Appl. Phys. Lett. 74, 3245 (1999).

${ }^{12}$ O. M. Khreis, R. J. Curry, M. Somerton, and W. P. Gillin, J. Appl. Phys. 88, 777 (2000).

${ }^{13}$ Z. Hong, C. Liang, R. Li, F. Zang, D. Fan, W. Li, L. S. Hung, and S. T. Lee, Appl. Phys. Lett. 79, 1942 (2001).

${ }^{14}$ F. X. Zang, Z. R. Hong, W. L. Li, M. T. Li, and X. Y. Sun, Appl. Phys. Lett. 84, 2679 (2004).

${ }^{15}$ O. M. Khreis, W. P. Gillin, M. Somerton, and R. J. Curry, Org. Electron. 2, 45 (2001).

${ }^{16}$ R. J. Curry and W. P. Gillin, Appl. Phys. Lett. 75, 1380 (1999).

${ }^{17}$ H. Wang, G. Qian, Z. Wang, J. Zhang, Y. Luo, and M. Wang, J. Lumin. 113, 214 (2005)

${ }^{18}$ B. S. Harrison, T. J. Foley, M. Bouguettaya, J. M. Boncella, J. R. Reynolds, K. S. Schanze, J. Shim, P. H. Holloway, G. Padmanaban, and S. Ramakrishnan, Appl. Phys. Lett. 79, 3770 (2001).

${ }^{19}$ R. G. Sun, Y. Z. Wang, Q. B. Zheng, H. J. Zhang, and A. J. Epstein, J. Appl. Phys. 87, 7589 (2000).

${ }^{20}$ W. P. Gillin and R. J. Curry, Appl. Phys. Lett. 74, 798 (1999).

${ }^{21}$ H. Suzuki, A. Yokoo, and M. Notomi, Polym. Adv. Technol. 15, 75 (2004).

${ }^{22}$ H. Suzuki, Y. Hattori, T. Iizuka, K. Yuzawa, and N. Matsumoto, Thin Solid Films 438-439, 288 (2003).

${ }^{23}$ R. J. Curry, W. P. Gillin, A. P. Knights, and R. Gwilliam, Appl. Phys. Lett. 77, 2271 (2000).

${ }^{24}$ R. J. Curry, W. P. Gillin, A. P. Knights, and R. Gwilliam, Opt. Mater. (Amsterdam, Neth.) 17, 161 (2001).

${ }^{25}$ R. J. Curry and W. P. Gillin, Synth. Met. 111-112, 35 (2000).

${ }^{26}$ H. Schift, L. J. Heyderman, M. Auf der Maur, and J. Gobrecht, Nanotechnology 12, 173 (2001).

${ }^{27}$ P. Del Carro, A. Camposeo, R. Stabile, E. Mele, L. Persano, R. Cingolani, and D. Pisignano, Appl. Phys. Lett. 89, 201105 (2006).

${ }^{28}$ R. Van Deun, P. Fias, P. Nockemann, A. Schepers, T. N. Parac-Vogt, K. Van Hecke, L. Van Meervelt, and K. Binnemans, Inorg. Chem. 43, 8461 (2004).

${ }^{29}$ R. Van Deun, P. Fias, K. Driesen, K. Binnemans, and C. Gorller-Walrand, Phys. Chem. Chem. Phys. 5, 2754 (2003).

${ }^{30}$ H. Neitzert, M. Ferrara, S. Bellone, A. Rubino, S. Concilio, P. Iannelli, P. Vacca, and L. Ferrara, Proc. SPIE 5840, 139 (2005). 